\title{
Prediction of Survival in Stage I Lung Carcinoma Patients by Telomerase Function Evaluation
}

\author{
Antonio Marchetti, Caterina Pellegrini, Fiamma Buttitta, Monica Falleni, \\ Solange Romagnoli, Lara Felicioni, Fabio Barassi, Simona Salvatore, \\ Antonio Chella, Carlo Alberto Angeletti, Massimo Roncalli, Guido Coggi, and \\ Silvano Bosari
}

Department of Oncology and Neurosciences (AM, FB, LF, FB, SS), University of Chieti, Chieti; Department of Medicine, Surgery, and Dental Sciences (CP, MF, SR, GC, SB), University of Milan, A.O.S. Paolo and IRCCS Ospedale Maggiore, Milan; Department of Surgery (AC, CAA), University of Pisa, Pisa; and Department of Medicine, Surgery, and Dental Sciences (MR), University of Milan, Istituto Clinico Humanitas, Rozzano (Milan), Italy

SUMMARY: Telomerase activity and telomerase reverse transcriptase (hTERT) expression are elevated in human malignancies. We have investigated telomerase activity measured by the telomeric repeat amplification protocol (TRAP) assay and hTERT levels by real-time RT-PCR in stage I non-small-cell lung carcinomas. The purposes of our study included the comparison of these two techniques in the assessment of telomerase function and the evaluation of their prognostic significance. Telomerase activity and hTERT levels were determined in 90 stage I non-small-cell lung carcinoma patients, using TRAP assay and real-time RT-PCR, respectively. Variables were analyzed by the $\chi^{2}$ and Fisher exact tests. Survival was analyzed by the Kaplan-Meier method. Multivariate analysis was performed with the Cox's proportional hazards model. Telomerase activity was elevated in 60 (67\%) carcinomas. hTERT was elevated in $43(48 \%)$ carcinomas. Only $21(23 \%)$ tumors had low telomerase function by both TRAP and hTERT expression levels. Telomerase activity and hTERT were significantly correlated $(p=0.017)$, although 35 cases displayed discordant results. Both telomerase activity and hTERT levels were significantly associated with poor patient overall and disease-free survival ( $p=0.019$ and $p=0.018$ for TRAP, and $p=0.011$ and $p=0.012$ for hTERT, respectively). Among the 21 patients with tumors displaying low telomerase function, defined by both TRAP and hTERT expression levels, only one succumbed to the disease $(p=0.0053)$. Our results suggest that the two techniques used in this study evaluate separate aspects of telomerase function and their combination provides powerful prognostic information in lung cancer patients. (Lab Invest 2002, 82:729-736).

\begin{abstract}
I ung carcinoma is the first cause of death by $L_{\text {cancer in developed countries, and its incidence is }}$ steadily increasing in the world (Greenlee et al, 2001). Patients' prognosis is largely dependent on the disease stage. The standard treatment regimen for $\mathrm{pa-}$ tients with a traditionally better outcome, those grouped as stage I non-small-cell lung cancer (NSCLC), is resection of the primary tumor without adjuvant therapy. This treatment can cure about twothirds of the patients with stage I disease, although the remaining $30 \%$ to $40 \%$ of the patients will have tumor recurrence and will die despite complete resection (Bunn et al, 1994; Strauss et al, 1995). Because careful pathologic examination of the primary lesions cannot
\end{abstract}

DOI: 10.1097/01.LAB.0000017165.26718.60

Received December 29, 2001.

The study has been supported by grants from Ministero dell'Istruzione, dell'Università e della Ricerca (MIUR-cofin 1999), and Associazione Italiana per la Ricerca sul Cancro (AIRC).

Address reprint requests to: Dr. Silvano Bosari, Division of Anatomic Pathology, A.O.S. Paolo, Via A. Di Rudinì 8, 20142 Milano, Italy. E-mail: silvano.bosari@unimi.it be used to accurately predict clinical outcome, there exists a great need to identify molecular markers with which to define a subset of stage I NSCLC patients as candidates for new investigational adjuvant therapies, eventually leading to an improvement in patient survival.

Much interest has recently focused on telomerase, a ribonucleoprotein enzyme that uses its own integral RNA as a template for synthesis of telomeric repeats to compensate for the normal loss of terminal DNA sequences during cell divisions (Greider and Blackburn, 1985; Morin, 1989). After the introduction of the PCR-based assay, called the telomeric repeat amplification protocol (TRAP), telomerase activity was found to be present in most human tumors (Piatyszek et al, 1995; Shay and Wright, 1996). Furthermore, a correlation between telomerase activity and clinical outcome in different malignancies has been reported (Clark et al, 1997; Hiyama et al, 1995a, 1995b). We have previously shown that telomerase activity, evaluated by the TRAP assay, is an independent prognostic marker in stage I NSCLC patients (Marchetti et al, 1999).

The constituents of the telomerase complex have recently been identified, and human telomerase re- 
verse transcriptase (hTERT) has been found to be responsible for the enzymatic activity of telomerase (Kilian et al, 1997; Nakamura et al, 1997; Nakayama et al, 1998). The expression of hTERT is thought to have important prognostic significance in different forms of human malignancies. In particular, hTERT mRNA overexpression evaluated by real-time PCR has been correlated with the histopathologic grade and receptor status in breast cancer, therefore identifying the tumors with more aggressive behavior (Bieche et al, 2000). An increase in hTERT mRNA expression was also correlated with the pathologic grade and clinical stage in bladder carcinomas, discriminating between low- and high-grade tumors and between superficial and muscle-invasive cancers (de Kok et al, 2000). A significant correlation between hTERT mRNA levels and telomerase activity was established in hepatocellular carcinomas (Hisatomi et al, 1999). Interestingly, these authors found a significant difference between tumor and non-neoplastic liver tissues, suggesting a possible application of hTERT quantification in the follow-up evaluation of patients at high risk to develop hepatocellular carcinomas. In prostate cancer, elevated hTERT levels were significant associated with myc overexpression, although both parameters were not correlated with tumor stage or Gleason grade (Latil et al, 2000).

In lung cancer, hTERT expression has been associated with telomerase activity, but no relationship with clinical and pathologic features has been reported (Arinaga et al, 2000). Recently, poor survival of lung cancer patients has been linked to high telomerase expression levels evaluated by in situ hybridization and immunohistochemistry, together with a semiquantitative TRAP assay (Kumaki et al, 2001). A shorter survival was observed in patients with hTERT expression, evaluated by nonquantitative RT-PCR, indicating that hTERT expression might be an independent negative prognostic factor (Komiya et al, 2000). The prognostic significance of hTERT mRNA levels, assessed by current quantitative techniques, in lung carcinomas has yet to be elucidated.

In this study we report a comprehensive analysis of the telomerase status, based on the evaluation of hTERT mRNA expression and telomerase activity, in stage I NSCLC. A large series of stage I NSCLC patients was investigated for hTERT mRNA expression by real-time RT-PCR and for telomerase activity by the TRAP assay. The purposes of our investigation included: (a) the evaluation of real-time RT-PCR for the quantitative assessment of hTERT; (b) the comparison of hTERT expression and telomerase activity in lung tumors; and (c) the assessment of the prognostic utility of these two parameters, both individually and combined.

The results of our investigation suggest that these two techniques evaluate separate aspects of telomerase function. Their combination provides a better overall assessment of telomerase function and powerful prognostic information in lung cancer patients.

\section{Results}

\section{hTERT Expression in Normal Lung and in Tumors}

Ten normal lung tissue samples were used to establish a basal level of hTERT mRNA. All of the normal samples expressed detectable, but very low levels of hTERT mRNA, ranging from $0.01 \mathrm{n}$ to $0.82 \mathrm{n}$.

Primary tumors from 90 stage I NSCLC patients were examined. Twenty-one $(23 \%)$ cases showed very low levels of hTERT mRNA, comparable to the normal counterparts, whereas 69 (77\%) tumors displayed hTERT levels higher than the normal samples. The range of hTERT levels varied greatly, ranging from $1 \mathrm{n}$ to $939 \mathrm{n}$. Setting a cut off at $2.6 \mathrm{n}$, a value that represents the median value of expression distribution of the lung tumors, $47(52 \%)$ cases had low hTERT expression and 43 (48\%) cases high hTERT expression. hTERT levels, excluding the highest one, which greatly exceeded the range in tumor samples, are shown in Figure 1. The differences between normal lung hTERT levels and low and high hTERT expression tumors are statistically significant $(p=0.00065$ and $p$ $=0.00001)$.

\section{Telomerase Activity}

A sample was considered positive for telomerase activity when the 36-bp internal control band (see "Materials and Methods") and a ladder of PCR products similar to that of the telomerase-positive control lane were present. Extracts that showed a 36-bp band but not ladders of PCR products were considered negative (Fig. 2).

Telomerase activity was detected in $60(67 \%)$ of the 90 tumors examined. There were no obvious differences in the ratio of tumor cells to stromal cells in the carcinomas with and without detectable telomerase activity, and the reproducibility of the TRAP assay was confirmed by sampling multiple different sites of some of the tumors.

\section{Comparative Evaluation of Techniques with Pathologic Correlation}

No correlation was observed between telomerase activity and/or hTERT expression and age, sex, smoking habits, tumor size, and tumor histotype. A trend suggesting an association between telomerase status and histopathologic grade of the tumors was observed, but data were not statistically significant. G1 tumors were scored positive in $20 \%$ of cases, whereas G2 and G3 tumors were positive in $42 \%$ and $38 \%$ of cases, respectively, $p=0.11$. Results are detailed in Table 1. According to the telomerase activity results, 21 cases were devoid of telomerase activity and hTERT expression, whereas 69 showed activity and/or expression. Applying a $\chi^{2}$ test, we observed a statistical link between hTERT expression and telomerase activity $(\rho=0.017)$, although 35 cases displayed discordant results (Table 2). 


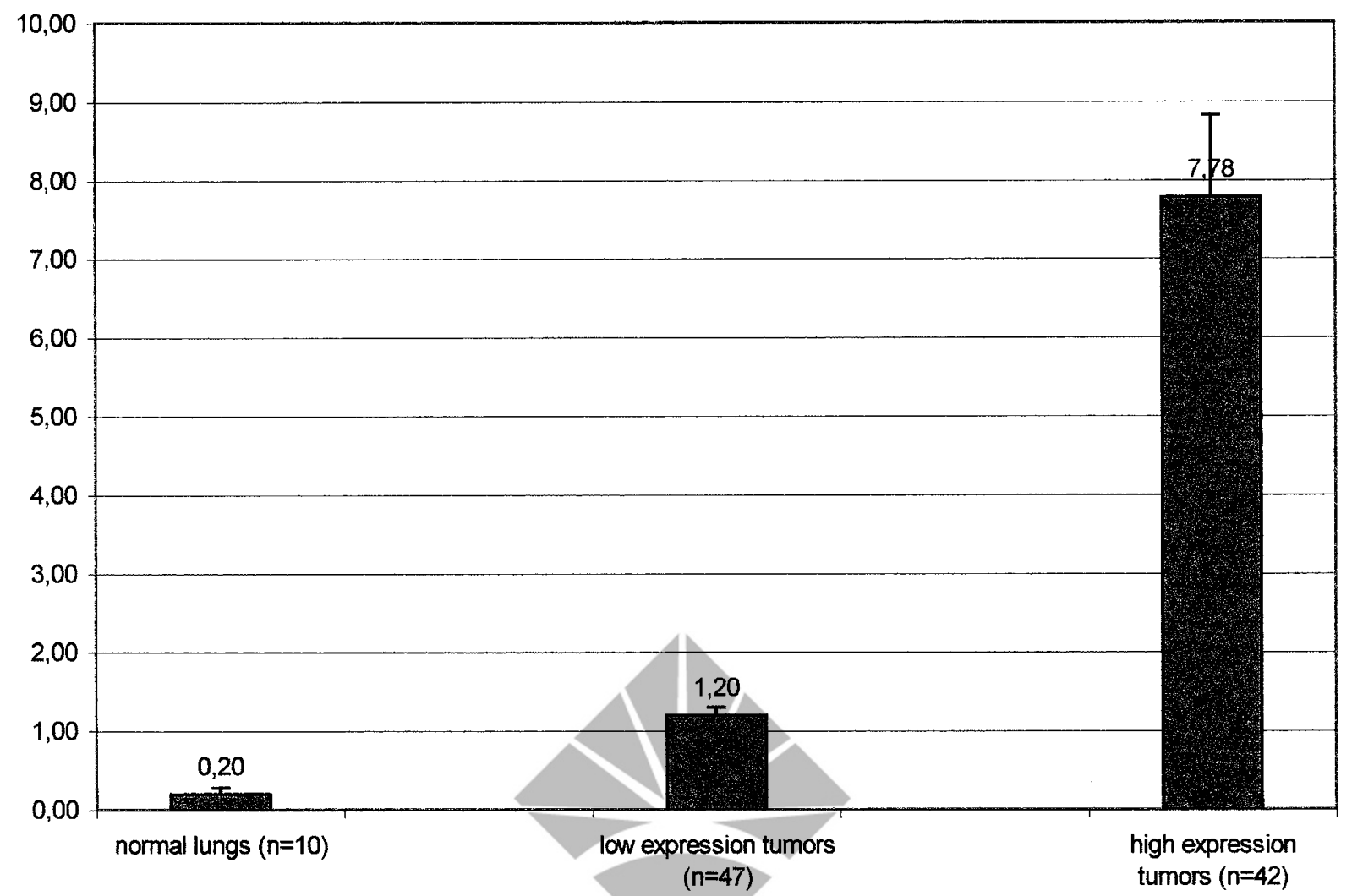

Figure 1.

Distribution of human telomerase reverse transcriptase (hTERT) expression levels in normal lung specimens, and in low- and high-expression tumors. Data are expressed as mean and standard error of the mean for each group. The tumor sample with extremely high expression level (939 $\mathrm{n}$ ) has been excluded from the high-expression group.

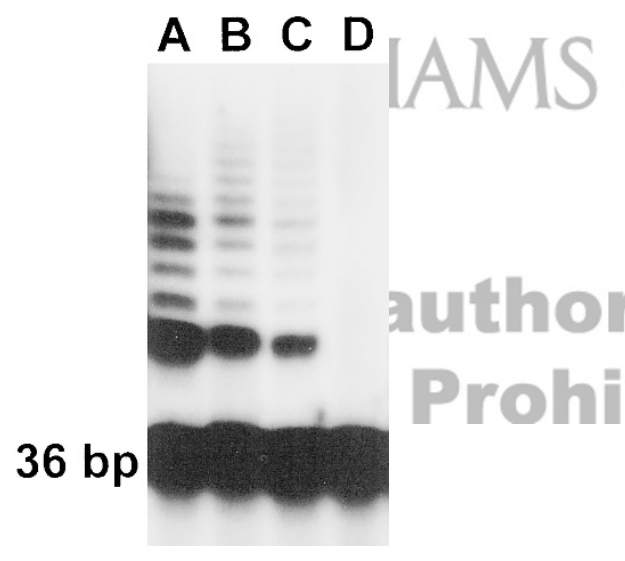

patients with tumors showing low telomerase function by both TRAP and hTERT expression levels, only one succumbed to the disease $(p=0.0053)$. Overall survival curves are shown in Figure 3.

A multivariate analysis, using Cox's proportional hazards regression model, was performed to investigate the independent prognostic factors among these markers: tumor stage, histology, histologic grade, and telomerase function. As a results, the presence of telomerase activity or hTERT levels were identified as the only two independent predictor factors of diseasefree survival ( $p=0.0317$, risk ratio, 3.36 [1.11-10.15]; and $p=0.0449$, risk ratio, 2.87 [0.91-8.76], respectively) and overall survival ( $p=0.0318$, risk ratio, 3.34 [1.09-10.08]; and $p=0.0457$, risk ratio, 2.84 [0.90-

Figure 2.

Telomeric repeat amplification protocol analyses of non-small-cell lung cancer specimens are shown. Tumors A, B, and C are examples of telomerase-positive lung carcinomas, Tumor $D$ represents a telomerase-negative case. The 36 -bp internal positive control band is present in every lane.

\section{Survival Analysis}

The Kaplan-Meier survival curves in all patients with stage I NSCLC defined a significant association between telomerase activity and both disease-free $(p=$ 0.018 ) and overall survival $(p=0.019)$. This correlation is preserved considering hTERT levels alone $p=$ 0.012 and $p=0.011$, respectively). Among the 21
8.69], respectively). A very strong association has been documented when considering both telomerase activity and hTERT expression and disease free survival $(p=0.0092$, risk ratio, 9.01 [1.16-71.43]) and overall survival ( $p=0.0095$, risk ratio, $8.62[1.12-$ 66.67]; Table 3).

\section{Discussion}

In the present study we have carried out a comprehensive analysis of telomerase function in a series of 90 stage I NSCLC lung cancer patients. We evaluated hTERT mRNA levels by real-time RT-PCR analysis and telomerase activity by TRAP assay. The specific goals 
Table 1. Comparison of Clinical and Pathological Variables with the Presence of Telomerase Activity and/or hTERT Expression in Stage I NSCLC Patients

\begin{tabular}{lccc}
\hline & \multicolumn{2}{c}{$\begin{array}{c}\text { Telomerase activity } \\
\text { and/or hTERT }\end{array}$} \\
& \multicolumn{2}{c}{ expression } & \\
\cline { 2 - 3 } \multicolumn{1}{c}{ Factor } & Negative & Positive & p value \\
\hline Age & $63.4 \pm 7.2$ & $63.1 \pm 6.4$ & NS (0.7534) \\
$\quad$ (mean \pm SD, yr) & & & \\
Sex & & & \\
Male & $19(90 \%)$ & $65(94 \%)$ & NS (0.6209) \\
Female & $2(10 \%)$ & $4(6 \%)$ & \\
Smoking habits & & & \\
Smoker & $13(68 \%)$ & $33(57 \%)$ & \\
Former smoker & $6(32 \%)$ & $24(41 \%)$ & NS (0.6070) \\
Nonsmoker & $0(0 \%)$ & $1(2 \%)$ & \\
Tumor stage & & & \\
IA & $6(29 \%)$ & $23(33 \%)$ & \\
IB & $15(71 \%)$ & $46(67 \%)$ & NS (0.7932) \\
Histology & & & \\
Squamous & $12(57 \%)$ & $37(54 \%)$ & NS (0.5288) \\
$\quad$ carcinoma & & & \\
Adenocarcinoma & $9(43 \%)$ & $28(40 \%)$ & \\
Large cell & $0(0 \%)$ & $4(6 \%)$ & \\
$\quad$ carcinoma & & & \\
Histologic grade & & & \\
G1 & $9(43 \%)$ & $14(20 \%)$ & \\
G2 & $7(33 \%)$ & $29(42 \%)$ & NS (0.1101) \\
G3 & $5(24 \%)$ & $26(38 \%)$ & \\
\hline
\end{tabular}

NS, not significant; NSCLC, non-small-cell lung cancer.

Table 2. hTERT Expression and Telomerase Activity in Stage I NSCLC

\begin{tabular}{|c|c|c|c|c|}
\hline \multirow{2}{*}{$\begin{array}{c}\text { HTERT } \\
\text { expression }\end{array}$} & \multicolumn{2}{|c|}{$\begin{array}{c}\text { Telomerase activity } \\
n /(\%)\end{array}$} & \multirow[b]{2}{*}{ Total $n /(\%)$} & \multirow[b]{2}{*}{$p$ value } \\
\hline & Positive & Negative & & \\
\hline High & $34(79)$ & $9(21)$ & $43(100)$ & 0.017 \\
\hline Low & $26(55)$ & $21(45)$ & $47(100)$ & \\
\hline
\end{tabular}

NSCLC, non-small-cell lung cancer.

of the study included the evaluation of real time RT-PCR for the quantitative assessment of hTERT, the comparison of the two techniques, and the assessment of their prognostic significance. We quantified the expression of the hTERT gene in 10 normal lung RNAs and 90 NSCLC RNAs. hTERT expression was present in all of the normal and tumor samples tested. However, all normal tissues and 21 (23\%) lung tumors showed very low $\mathrm{hTERT}$ expression levels by real-time RT-PCR. When tumors were subdivided into two groups with low and high hTERT expression, according to the median value of expression distribution, a significant association was observed between high hTERT levels and shorter periods of disease-free and overall survival. To the best of our knowledge, this is the first report on the prognostic meaning of hTERT expression evaluated by real-time RT-PCR in NSCLC

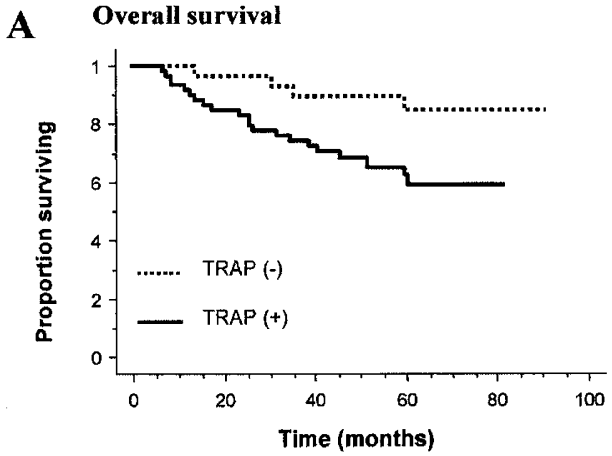

B Overall survival

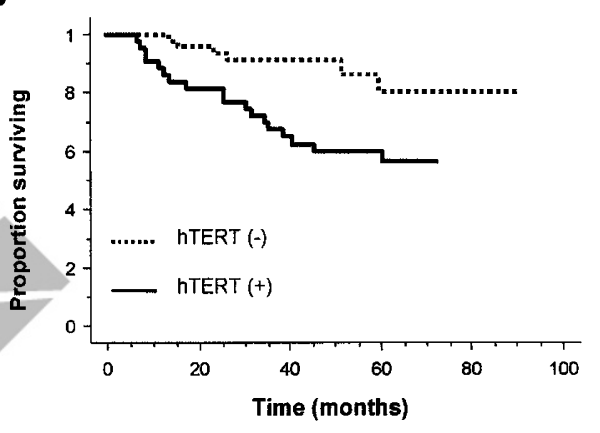

$1 \mathrm{C}_{\mathrm{C}}$ Overall survival

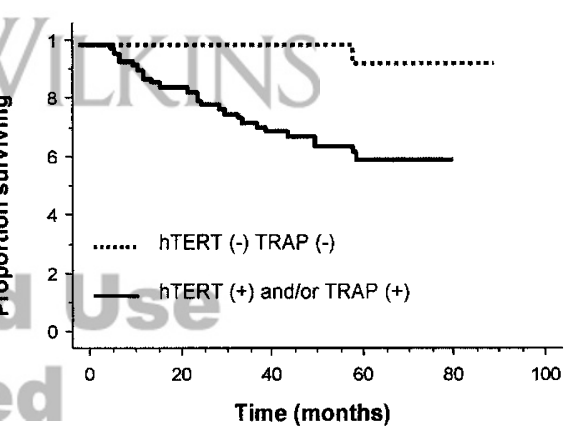

Figure 3.

Overall survival curves according to the telomerase activity status by telomeric repeat amplification protocol (TRAP) assay (A), hTERT mRNA expression levels $(B)$ and telomerase function, combining both telomerase activity and hTERT levels (C). All survival curve differences are statistically significant (see text for details).

patients. Our data are in keeping with those recently reported using the same methodologic approach on a series of 134 breast cancer patients: high hTERT levels in primary tumors were found to be significantly associated with shorter relapse-free survival (Bieche et al, 2000). A correlation between real-time quantitative measurement of hTERT and clinicopathologic parameters of poor prognosis, such as histologic grade and muscle invasion, has also been observed in bladder urothelial cell carcinomas (de Kok et al, 2000). 
Table 3. Statistical Analysis of Prognostic Markers and Clinical Outcome in Stage I NSCLC Patients

\begin{tabular}{|c|c|c|c|c|}
\hline \multirow[b]{2}{*}{ Factor } & \multicolumn{2}{|c|}{ Disease-free survival } & \multicolumn{2}{|c|}{ Overall survival } \\
\hline & $p$ & Risk ratio & $p$ & Risk ratio \\
\hline Tumor stage (IA, IB) & NS $(0.2347)$ & $1.70(0.71-4.09)$ & NS $(0.2204)$ & $1.73(0.72-4.17)$ \\
\hline Histologic grade & NS $(0.7455)$ & $1.19(0.42-3.38)$ & NS $(0.8845)$ & $1.08(0.38-3.09)$ \\
\hline Histotype & NS $(0.5368)$ & $1.27(0.47-3.49)$ & NS $(0.4339)$ & $1.32(0.49-3.68)$ \\
\hline Telomerase activity and/or hTERT expression & 0.0092 & $9.01(1.16-71.43)$ & 0.0095 & $8.62(1.12-66.67)$ \\
\hline
\end{tabular}

NSCLC, non-small-cell lung cancer.

In this series of 90 NSCLC patients, telomerase activity, evaluated by an isotopic TRAP method, was present in $67 \%$ of cases and was found to be a predictor of clinical outcome, in keeping with our previous data (Marchetti et al, 1999). Because we found an expression of the hTERT gene in all of the samples, whereas telomerase activity was evident in $67 \%$ of the tumors, our data indicate that the sensitivity of the real-time RT-PCR method is much higher than that of the TRAP assay. The relationship between telomerase activity, detected by TRAP, and hTERT expression, investigated by real-time RT-PCR, in human tumors in vivo has been studied only in a limited number of cases. In 24 hepatocellular carcinoma samples Hisatomi et al (1999) found a significant correlation between the levels of hTERT mRNA and that of telomerase activity $(r=0.751)$. More recently, in agreement with our data, Buchler et al (2001) reported that in 29 pancreatic carcinomas the TRAP assay was positive in $35 \%$ of cases, whereas hTERT expression was present in $90 \%$ of cases. In our series of tumors, a significant association between high levels (above the median value) of hTERT expression and telomerase activity was observed, however, in $39 \%$ of cases results were discordant. These discrepancies may be explained by the following possibilities: (1) A high expression of hTERT in the absence of telomerase activity may be due to the presence of telomerase inhibitors in the tissue extract that may block the enzyme during the TRAP assay (Hohaus et al, 1996; Lancelin et al, 2000). (2) Low levels of hTERT gene expression in tumors with telomerase activity could be a consequence of the fact that hTERT mRNA and the catalytic subunit of the enzyme have different half-life periods.

We decided to evaluate the combined results obtained by TRAP and real-time RT-PCR: a stronger association between telomerase status and diseasefree and overall survival has emerged. In particular, among the 21 patients who were scored negative with both methods, only 1 succumbed to the disease $(p=$ 0.0053). Therefore, taken in a broad sense, telomerase alterations (overexpression and/or activity), which we call here telomerase function, are frequent events in NSCLC and strongly correlate with disease-free and overall survival. The results of the present study indicate that both techniques (real-time RT-PCR and TRAP assay) are indicated to provide the most accurate estimation of telomerase status in NSCLC. The use of a single technique could underestimate the actual number of telomerase abnormalities in lung tumors. However, our data show that both methods used separately can give useful prognostic information.

The quantitative assessment of mRNA levels in human tissues by real-time RT-PCR may be hampered by the heterogeneity of samples, almost always containing both neoplastic and non-neoplastic cell populations. In our study we examined only samples in which tumor cells comprised at least $80 \%$ of the specimen, thus greatly reducing tissue heterogeneity. Indeed our results document hTERT levels much higher in tumor specimens than in non-neoplastic ones. In future investigations, for cases in which tissue heterogeneity is quantitatively more significant, the cell populations to be studied may be enriched using laser microdissection or flow cytometry and cell sorting techniques.

Real-time RT-PCR provides several advantages to quantify gene expression: (a) it does not require postPCR sample handling, thereby avoiding problems related to carryover; (b) it has a high sample throughput and possesses a wide dynamic range, so that samples do not have to contain equal initial amounts of total RNA; (c) it makes RNA quantitation more precise and reproducible, because it is based on the threshold cycle values established in the early exponential phase of the PCR reaction (Gibson et al, 1996). At the present time, few papers have been published on hTERT expression evaluated by real-time RT-PCR in human tumors, and no data are available for lung cancer.

It is important to point out that the real-time RT-PCR technique has several advantages over the TRAP assay, in that it is faster, more reproducible, less sensitive to RNase activity, proteases, and protein inhibitors, and it can be applied to archival material for retrospective analyses (Specht et al, 2001). The TRAP assay may suffer some limitations primarily due to inefficient extraction, PCR inhibitors, telomerase inhibitors, and telomerase degradation in clinical samples. In addition, the TRAP assay provides only semiquantitative data for telomerase activity evaluation (Wu et al, 2000).

In conclusion, using real-time quantitative RT-PCR, we have shown that the hTERT gene plays a major role in lung cancer progression. In particular, we found evidence that hTERT mRNA expression may serve as a new prognostic tool for stage I NSCLC patients. In addition, we demonstrated that telomerase activity is 
significantly associated with hTERT expression and poor prognosis, but does not always reflect the status of hTERT mRNA. Finally, we brought evidence that a new parameter obtained by cumulating the results of the real-time RT-PCR and the TRAP assay is a strong indicator of clinical outcome. These new prognostic markers should be considered in future prospective trials to define high-risk stage I NSCLC patients who could benefit from adjuvant therapy.

\section{Materials and Methods}

\section{Study Population}

The primary NSCLC specimens were obtained from 90 patients with pathologic stage I NSCLC surgically treated at the Department of Surgery, University of Pisa (Pisa, Italy) between 1993 and 1994. In each case, tumor and macroscopically normal lung tissue samples (taken as far as possible from the neoplastic area) were snap-frozen in liquid nitrogen within 10 minutes of excision and stored at $-80^{\circ} \mathrm{C}$. Immediately adjacent pieces of tumor and normal tissue were fixed and processed for light microscopy. In all tumor specimens the amount of tumor cells equaled or exceeded $80 \%$ of the overall sample, confirmed by histopathologic examination. Similarly, all of the macroscopically normal samples were judged to be benign.

The study population consisted of $84(93 \%)$ men and $6(7 \%)$ women, with a mean age of 63.3 years (range, 43 to 74 years). Patients underwent lobectomy ( $85 \%$ of cases) or pneumonectomy (15\% of cases) with hylar and mediastinal lymph node sampling. Patient stage at the time of diagnosis was determined according to the guidelines of the American Joint Committee on Cancer (Fleming et al, 1997). Histologic type and tumor cell differentiation were determined according to the WHO criteria (Travis et al, 1999). The most common histologic type was squamous cell carcinoma (49 cases, 54\%), followed by adenocarcinoma (37 cases, $41 \%$ ) and large cell carcinoma (4 cases, $5 \%)$. Twenty-three (26\%) tumors were well differentiated (G1), 36 (40\%) moderately differentiated (G2), and 31 (34\%) poorly differentiated (G3). Smoking history was available for 77 patients: $46(60 \%)$ were smokers, $30(39 \%)$ were former smokers (stopped smoking at least 1 year before the diagnosis of lung cancer), and 1 (1\%) was a nonsmoker.

Follow-up data of the study population were obtained by direct patient contact. Follow-up occurred at 2-month intervals for the initial 2 years and at 4-month intervals afterward. Recurrences were detected by computed tomography scans or scintigrams and confirmed by pathologic examination, using biopsy specimens. Patients were categorized as alive with evidence of disease, alive without disease, and dead as a result of lung carcinoma. No patient in this series died of cancer-unrelated causes. Time in days from the date of the operation to the date of follow-up or death was recorded. The median follow-up in the series of patients examined was 54 months (range, 7 to 94 months).

\section{TRAP Assay}

Frozen tissue samples (50 to $100 \mathrm{mg}$ ) were homogenized with a pestle in $100 \mu \mathrm{l}$ ice-cold CHAPS lysis buffer $(0.5 \%$ CHAPS, $0.1 \mathrm{~mm}$ benzamidine, $10 \mathrm{~mm}$ Tris/ $\mathrm{HCl} \mathrm{pH} \mathrm{7.5,} 1 \mathrm{~mm} \mathrm{MgCl}_{2}, 1 \mathrm{~mm}$ EGTA, $10 \%$ glycerol, $5 \mathrm{~mm} \beta$-mercaptoethanol). After maintenance at $4^{\circ} \mathrm{C}$ for 30 minutes, the lysate was centrifuged at $12,000 \times g$ for 20 minutes at $4^{\circ} \mathrm{C}$. The supernatant was removed and its protein concentration was measured with the Biorad protein assay kit (Biorad Laboratories, Munchen, Germany). The supernatant fluid samples were diluted to a concentration of $0.3 \mu \mathrm{g} / \mu \mathrm{l}$ with lysis buffer and stored at $-80^{\circ} \mathrm{C}$. Telomerase activity was assayed by using the Oncor TRAP-eze telomerase detection kit (Oncor, Gaithersburg, Maryland; catalogue no. S7700). The presence of a primer and a template for amplification in the TRAP-eze kit resulted in the formation of a 36-bp band in every lane and served as internal control to identify false negatives due to the presence of Taq polymerase inhibitors.

\section{Real-Time RT-PCR}

hTERT expression in these tumors was measured by real-time quantitative RT-PCR, based on TaqMan methodology, using the ABI PRISM 7700 Sequence Detection System (Applied Biosystems, Foster City, California). This technique allows, by means of fluorescence emission, to find the cycling point when PCR product is detectable $\left(\mathrm{C}_{\mathrm{t}}\right.$ value or threshold cycle). As previously reported, the $C_{t}$ value correlates to the starting quantity of the target mRNA (Heid et al, 1994). To normalize the amount of total RNA present in each reaction, we amplified the housekeeping gene $\beta$-actin, which is assumed to be constant in both normal samples and lung tumors.

Our results are expressed as relative levels of hTERT mRNA, referred to a sample, called calibrator, chosen to represent $1 \mathrm{X}$ expression of this gene. The calibrator used was a lung carcinoma of the tissue collection under study, arbitrarily selected, that was analyzed on every assay plate with the unknown samples. All of the analyzed tumors express $n$-fold hTERT mRNA relative to the calibrator. Furthermore, one specific lung tumor sample was included in each run as control of reproducibility among experiments performed at different times.

The amount of target, normalized to an endogenous reference ( $\beta$-actin) and relative to the calibrator is defined by the $\Delta \Delta \mathrm{C}_{\mathrm{t}}$ method as described by Livak $\mathrm{K}$ (Sequence Detector User Bulletin 2; Applied Biosystems). Specifically, the formula is applied as follows:

$$
\text { target amount }=2^{-\Delta \Delta C}
$$

where $\Delta \Delta \mathrm{C}_{\mathrm{t}}=\left\{\left[\mathrm{C}_{\mathrm{t}}(\mathrm{hTERT}\right.\right.$ sample $)-\mathrm{C}_{\mathrm{t}}(\beta$-actin sample $)]-\left[\mathrm{C}_{\mathrm{t}}(\mathrm{hTERT}\right.$ calibrator $)-\mathrm{C}_{\mathrm{t}}(\beta$-actin calibrator $\left.\left.)\right]\right\}$.

This method is based on the assumption that the target (hTERT) and $\beta$-actin display equal amplification efficiencies. To verify this condition, we checked $\Delta C_{t}$ $\left(C_{t}\right.$ hTERT $-C_{t} \beta$-actin) variations according to tem- 
plate dilution. To this end, we prepared a standard curve, composed of five different dilutions of MCF-7 total RNA, corresponding to $100,25,6.25,1.6$, and 0.4 $\mathrm{ng}$. The slope of this curve was 0.049 . To assure the appropriate amplification efficiency, the slope of the standard curve should be $<0.1$.

\section{RNA Extraction}

Total RNA was extracted from frozen lung specimen by using a commercial kit, Trizol (Life Technologies, Gibco BRL), according to the manufacture's protocol. RNA was quantified spectrophotometrically, and its quality was checked by electrophoresis through denaturing agarose gels. Only samples not degraded, that showed clear $18 \mathrm{~S}$ and $28 \mathrm{~S}$ bands under ultraviolet light, were used for real-time RT-PCR.

\section{cDNA Synthesis}

Total RNA (200 ng) was reverse-transcribed in a total volume of $50 \mu \mathrm{l}$ containing $1 \mathrm{X}$ TaqMan buffer, $5.5 \mathrm{~mm}$ $\mathrm{MgCl} 2,1 \mathrm{~mm}$ deoxynucleotides, $2.5 \mu \mathrm{M}$ random hexamers, 20 units RNase inhibitor, 62.5 units MuLv reverse transcriptase. The samples were incubated at $25^{\circ} \mathrm{C}$ for 10 minutes, $48^{\circ} \mathrm{C}$ for 30 minutes, and $95^{\circ} \mathrm{C}$ for 5 minutes.

\section{PCR Amplification}

PCR was performed in a total volume of $50 \mu \mathrm{l}$ con-

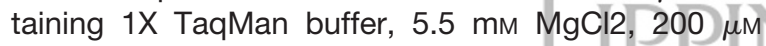
dATP, dCTP, dGTP, and $400 \mu \mathrm{M}$ dUTP, $300 \mathrm{~nm}$ each primer, $100 \mathrm{~nm}$ probe, 0.5 units of AmpErase Uracil $\mathrm{N}$-glycosilase (UNG), 1.25 units AmpliTãq/Gold, and $10 \mu \mathrm{l}$ of cDNA. Both $\beta$-actin and hTERT amplification were performed in duplicate for each sample.

The thermal cycling conditions included 2 minutes at $50^{\circ} \mathrm{C}$ and 10 minutes at $95^{\circ} \mathrm{C}$, followed by 40 cycles of $95^{\circ} \mathrm{C}$ for 15 seconds and $60^{\circ} \mathrm{C}$ for 1 minute. All reagents used for RT-PCR were purchased from Applied Biosystems.

\section{Primers and Probes}

Primers and probe for $\beta$-actin and hTERT mRNAs were chosen using a computer program, Primer Express (Applied Biosystems) The primers, placed in different exons, were tested not to amplify genomic DNA. Primers and probe nucleotide sequences for hTERT (GenBank accession number AF015950) were: forward primer 5'CACGCGAAAACCTTCCTCA-3' (placed in exon 10; $n t$ 2690-2708), reverse primer 5'-CAAGTTCACCACGCAGCC-3', TaqMan probe 5'(FAM)-CTCAGGGACACCTCGGACCAGGGT-(TAMRA)3' (both placed in exon 11; nt 2755-2738 and nt 2734-2711, respectively).

Primers and probe for $\beta$-actin mRNA (GenBank accession number X00351) were: forward primer 5'-TCCTTCCTGGGCATGGAG-3', reverse primer 5'- AGGAGGAGCAATGATCTTGATCTT-3', TaqMan probe 5'(FAM)-CCTGTGGCATCCACGAAACTACCTTC-(TAMRA)3'. Probes were purchased from Applied Biosystems.

\section{Statistical Analysis}

The different variables of the tumors analyzed were tested for association using the $\chi^{2}$ and Fisher exact tests. Overall survival was estimated by the method of Kaplan-Meier (Kaplan and Meier, 1958) and differences between curves were tested for statistical significance with the log-rank test (Cox and Oakes, 1984). Cox's proportional hazards regression models (Cox, 1972) were used to assess the independent prognostic contribution of clinicopathologic variables. The statistical analysis was performed using the StatView 5 statistical software run on a PowerPC G4 Macintosh computer.

\section{References}

Arinaga M, Shimizu S, Gotoh K, Haruki N, Takahashi T, Takahashi T, and Mitsudomi T (2000). Expression of human telomerase subunit genes in primary lung cancer and its clinical significance. Ann Thorac Surg 70:401-405.

Bieche I, Nogues C, Paradis V, Olivi M, Bedossa P, Lidereau $\mathrm{R}$, and Vidaud M (2000). Quantitation of hTERT gene expression in sporadic breast tumors with a real-time reverse transcription-polymerase chain reaction assay. Clin Cancer Res 6:452-459.

Buchler P, Conejo-Garcia JR, Lehmenn G, Muller M, Emrich T, Reber HA, Buchler MW, and Friess H (2001). Real-time quantitative PCR of telomerase mRNA is useful for the differentiation of benign and malignant pancreatic disorders. Pancreas 22:331-340.

Bunn PA, Van Zandwijk N, Pastorino U, Aisner J, Alberto P, Arriagada R, Carney D, Cornis R, Dittrich C, and Gatzemeier $U$ (1994). A first Euro-American forum on lung cancer treatment. Eur J Cancer 30A:710-713.

Clark GM, Osborne CK, Levitt D, Wu F, and Kim NW (1997). Telomerase activity and survival of patients with nodepositive breast cancer. J Natl Cancer Inst 89:1874-1881.

Cox DR (1972). Regression models and life-tables. J R Stat Soc 34:187-200.

Cox DR and Oakes D (1984). Analysis of survival data. New York: Chapman and Hall.

de Kok JB, van Balken MR, Roelofs RW, van Aarssen YA, Swinkels DW, and Klein Gunnewiek JM (2000). Quantification of hTERT mRNA and telomerase activity in bladder washings of patients with recurrent urothelial cell carcinomas. Clin Chem 46:2003-2007.

Fleming ID, Cooper JS, Henson DE, Hutter RVP, Kennedy BJ, Murphy GP, O'Sullivan B, Sobin LH, and Yarbro JW, editors (1997). American Joint Committee on Cancer: Cancer staging manual, 5th ed. Philadelphia: Lippincott-Raven.

Gibson UEM, Heid CA, and Williams PM (1996). A novel method for real time RT-PCR. Genome Res 6:995-1001.

Greenlee RT, Hill-Harmorn MB, Murray T, and Thun M (2001). Cancer statistics 2001. CA Cancer J Clin 51:15-36.

Greider CW and Blackburn EH (1985). Identification of a specific telomere terminal transferase activity in tetrahymena extracts. Cell 43:405-413.

Heid CA, Stevens J, Livak KJ, and Williams PM (1994). Real time quantitative PCR. Genome Res 6:986-994. 
Hisatomi H, Nagao K, Kanamaru T, Endo H, Tomimatsu M, and Hikiji K (1999). Levels of telomerase catalytic subunit mRNA as a predictor of potential malignancy. Int $\mathrm{J}$ Oncol 14:727-732.

Hiyama E, Hiyama K, Yokoyama T, Matsuura Y, Piatyszek MA, and Shay JW (1995a). Correlating telomerase activity levels with human neuroblastoma outcomes. Nature Med $1: 249-255$.

Hiyama E, Yokoyama T, Tatsumoto N, Hiyama K, Imamura Y, and Murakami $Y$ (1995b). Telomerase activity in gastric cancer. Cancer Res 55:3258-3262.

Hohaus S, Cavallo S, Bellacosa A, Genuardi M, Galli J, Cadoni G, Almadori G, Lauriola L, Litwin S, Maurizi M, and Neri G (1996). Telomerase activity in human laryngeal squamous cell carcinomas. Clin Cancer Res 2:1895-1900.

Kaplan EL and Meier PL (1958). Nonparametric estimation from incomplete observations. J Am Stat Assoc 53:457-481.

Kilian A, Bowtell DD, Abud HE, Hime GR, Venter DJ, Keese PK, Duncan EL, Reddel RR, and Jefferson RA (1997). Isolation of a candidate human telomerase catalytic subunit gene, which reveals complex splicing patterns in different cell types. Hum Mol Gen 6:2011-2019.

Komiya T, Kawase I, Nitta T, Yasumitsu T, Kikui M, Fukuoka M, Nakagawa K, and Hirashima T (2000). Prognostic significance of hTERT expression in non-small cell lung cancer. Int J Oncol 16:1173-1177.

Kumaki F, Kawai T, Hiroi S, Shinomiya N, Ozeki Y, Ferrans VJ, and Torikata C (2001). Telomerase activity and expression of human telomerase RNA component and human telomerase reverse transcriptase in lung carcinomas. Hum Pathol 32:188-195.

Lancelin F, Anidjar M, Villette JM, Soliman A, Teillac P, Le Duc A, Fiet J, and Cussenot O (2000). Telomerase activity as a potential marker in preneoplastic bladder lesions. BJU Int 85:526-531.

Latil A, Vidaud D, Valeri A, Fournier G, Vidaud M, Lidereau R, Cussenot O, and Biache I (2000). htert expression correlates with MYC over-expression in human prostate cancer. Int $\mathrm{J}$ Cancer 89:172-176.

Marchetti A, Bertacca G, Buttitta F, Chella A, Quattrocolo G, Angeletti CA, and Bevilacqua G (1999). Telomerase activity as a prognostic indicator in stage I non-small cell lung cancer. Clin Cancer Res 5:2077-2081.
Morin GB (1989). The human telomere terminal transferase enzyme is a ribonucleoprotein that synthesizes TTAGGG repeats. Cell 59:521-529.

Nakamura TM, Morin GB, Chapman KB, Weinrich SL, Andrews WH, Lingner J, Harley CB, and Cech TR (1997). Telomerase catalytic subunit homologs from fission yeast and human. Science 277:955-959.

Nakayama J, Tahara H, Tahara E, Saito M, Ito K, Nakamura H, Nakanishi T, Tahara E, Ide T, and Ishikawa F (1998). Telomerase activation by hTRT in human normal fibroblast and hepatocellular carcinomas. Nat Genet 18:65-68.

Piatyszek MA, Kim NW, Weinrich SL, Hiyama K, Hiyama E, Wright WE, and Shay JW (1995). Detection of telomerase activity in human cells and tumors by a telomeric repeat amplification protocol (TRAP). Methods Cell Sci 17:1-15.

Shay JW and Wright WE (1996). Telomerase activity in human cancer. Curr Opin Oncol 8:66-71.

Specht K, Richter T, Muller U, Walch A, Werner M, and Hofler $H$ (2001). Quantitative gene expression analysis in microdissected archival formalin-fixed and paraffin-embedded tumor tissue. Am J Pathol 158:419-429.

Strauss GM, Kwiatkowski DJ, Harpole DH, Lynch TJ, Skarin AT, and Sugarbaker DJ (1995). Molecular and pathologic markers in stage-I non-small-cell carcinoma of the lung. J Clin Oncol 13:1265-1279.

Travis TD, Colby TV, Corrin B, Shimosato Y, and Brambilla E (1999). Histological classification of lung and pleural tumors. In: Travis WD, editor. WHO international histological classification of tumors: Histological typing of lung and pleural tumors, 3rd ed. Berlin: Springer, 21-26.

Wu YY, Hruszkewycz AM, Delgado RM, Yang A, Vortmeyer AO, Moon YW, Weil RJ, Zhuang Z, and Remaley AT (2000). Limitations on the quantitative determination of telomerase activity by the electrophoretic and ELISA based TRAP assays. Clin Chim Acta 293:199-212. 